\title{
Opioid-free anesthesia in oncologic surgery: the rules of the game
}

\author{
Alessandro De Cassai ${ }^{*}$ (D), Federico Geraldini', Serkan Tulgar ${ }^{2}$, Ali Ahiskalioglu ${ }^{3,4}$, Edward R. Mariano ${ }^{5,6}$, \\ Burhan Dost ${ }^{7}$, Pierfrancesco Fusco ${ }^{8}$, Gian Marco Petroni ${ }^{9}$, Fabio Costa ${ }^{10}$ and Paolo Navalesi ${ }^{1,11}$
}

\begin{abstract}
Background: Opioids are frequently used in the postoperative period due to their analgesic properties. While these drugs reduce nociceptive somatic, visceral, and neuropathic pain, they may also lead to undesirable effects such as respiratory depression, urinary retention, nausea and vomiting, constipation, itching, opioid-induced hyperalgesia, tolerance, addiction, and immune system disorders. Anesthesiologists are in the critical position of finding balance between using opioids when they are necessary and implementing opioid-sparing strategies to avoid the known harmful effects. This article aims to give an overview of opioid-free anesthesia.

Main body: This paper presents an overview of opioid-free anesthesia and opioid-sparing anesthetic techniques. Pharmacological and non-pharmacological strategies are discussed, highlighting the possible advantages and drawbacks of each approach.

Conclusions: Choosing the best anesthetic protocol for a patient undergoing cancer surgery is not an easy task and the available literature provides no definitive answers. In our opinion, opioid-sparing strategies should always be implemented in routine practice and opioid-free anesthesia should be considered whenever possible. Nonpharmacological strategies such as patient education, while generally underrepresented in scientific literature, may warrant consideration in clinical practice.
\end{abstract}

Keywords: Opioids, Anesthesia, Cancer, Review

\section{Introduction}

Moderate to severe pain is reported to occur in $30-80 \%$ of patients on the first postoperative day [1]. If postoperative pain is not appropriately managed, it may lead to central sensitization and chronic postsurgical pain [2]. Opioids are frequently used in the postoperative period due to their analgesic properties. While these drugs reduce nociceptive somatic, visceral, and neuropathic pain, they may also lead to undesirable effects such as respiratory depression, urinary retention, nausea and vomiting, constipation, itching, opioid-induced hyperalgesia, tolerance, addiction, and immune system disorders [3]. Moreover, excessive prescribing has contributed to the

\footnotetext{
* Correspondence: alessandro.decassai@aopd.veneto.it

${ }^{1}$ UOC Anaesthesia and Intensive Care Unit, University Hospital of Padua, Via Giustiniani 1, 35127 Padua, Italy

Full list of author information is available at the end of the article
}

opioid epidemic that has primarily affected people in North America [4, 5]. Enhanced Recovery After Surgery (ERAS) protocols recommend avoiding long acting or high doses of opioids in order to reduce their side effects in the postoperative period [6,7].

Anesthesiologists are therefore in the critical position of balancing the judicious use of opioids when they are indicated while avoiding opioid-related harm and effectively managing pain. There are a number of methods or approaches that can be used to reduce opioid use before, during, and after surgery. These include identifying and optimizing individuals at risk of long-term opioid dependence and using a multimodal non-opioid analgesic regimen perioperatively $[8,9]$. In this framework, opioidfree anesthesia (OFA) may be an interesting approach to cancer patients and is an active field of research. This article aims to give an overview of OFA and of opioid-

(c) The Author(s). 2022 Open Access This article is licensed under a Creative Commons Attribution 4.0 International License, which permits use, sharing, adaptation, distribution and reproduction in any medium or format, as long as you give appropriate credit to the original author(s) and the source, provide a link to the Creative Commons licence, and indicate if changes were made. The images or other third party material in this article are included in the article's Creative Commons licence, unless indicated otherwise in a credit line to the material. If material is not included in the article's Creative Commons licence and your intended use is not permitted by statutory regulation or exceeds the permitted use, you will need to obtain permission directly from the copyright holder. To view a copy of this licence, visit http://creativecommons.org/licenses/by/4.0/ 
sparing strategies more generally. Both the pharmacological and non-pharmacological strategies will be discussed, highlighting possible advantages and drawbacks of these approaches.

\section{Main text}

\section{Rationale}

Cancer is one of the most common causes of mortality worldwide leading to an estimated 10 million deaths in 2020 [10]. Surgery is an important element of treatment in these patients. With the emergence of new surgical and technological developments, the frequency of oncological surgeries is also increasing. Analgesia management in oncological surgery differs in some aspects when compared to other surgical procedures, as this group of patients are frequently prescribed opioids during the preoperative period for the management of cancer-related pain. Also, malnutrition, depression secondary to chronic illness and other physiological changes affect the pharmacokinetics of drugs in general. Opioids have been associated with several problems: dose-dependent side effects that may be debilitating and delay rehabilitation; negative impact on nociceptive pathways with dose-dependent hyperalgesia and insufficient efficacy in reducing incident pain. Moreover, many patients among the broad surgical population may have a considerable advantage from OFA, in particular morbidly obese, patients with sleep apnoea and/or chronic obstructive pulmonary disease, and the acute/chronic opioid addicted [11]. Opioids are also thought to interfere with the immune system which may have a negative impact on infectious or cancerous diseases; opioids might bind to opioid receptors expressed by tumor cells; thus, opioid use in oncological patients may favor tumor angiogenesis, growth, and spreading of micrometastasis. Hence, cancer patients may take the greatest advantage from this technique [12].

OFA technique is feasible following the basic concept of multimodal analgesia that one drug alone cannot completely replace opioids. An adequate association of drugs, possibly with the concurrent use of regional anesthesia techniques, permits a good quality of anesthesia without using opioids. The multimodal approach blocks or mitigates the transmission of pain and inflammatory pathways at different levels, reducing or eliminating (in the case of OFA) opioid requirements [13].

OFA has been shown to be feasible but only few welldesigned studies have been published so far and very little data is available on long-term outcomes (incidence of hyperalgesia and persistent pain; opioid abuse; cancer recurrence and survival outcomes). The overall literature remains scarce and whether OFA is clinically advantageous or not in the different fields of application and with different modalities is yet to be established.
The use of OFA techniques may be appropriate in certain surgeries for cancer patients, especially if regional anesthesia and more generally opioid-sparing strategies can be employed. Preclinical trials have suggested that opioids inhibit the function of natural killer cells and increase cancer recurrence by affecting angiogenesis and tumor cell signaling pathways. On the other hand, regional anesthesia is thought to contribute positively to outcomes in cancer patients by reducing surgical stress response and thus reducing the need for volatile anesthetics and opioids [14]. However, a meta-analysis showed insufficient evidence to recommend any analgesia technique for patients undergoing cancer surgery [15]. The popularity of OFA has increased among anesthesiologists worldwide recently.

However, differences in definitions have led to conflicting results. Its benefits, limitations, and applicability have been questioned, with some studies reporting that it does not provide any benefits [9]. However, in a meta-analysis, strict opioid-free anesthesia was found to significantly reduce postoperative morphine consumption and postoperative adverse events in selected surgeries without increasing intraoperative adverse events, postoperative pain, and discharge time from the post-anesthesia care unit [16]. Although there are many studies regarding OFA techniques related to drugs and regional and nonpharmacological options, meta-analyses have failed to report solid recommendations or suggestions. It is obvious that further studies are required to determine whether patient characteristics should be used to create individualized analgesia regimens or if a common single modality should be adopted for a majority of or for all patients.

\section{Intravenous agents}

Dexmedetomidine is a potent and highly selective $\alpha-2$ adrenoreceptor agonist with sedative, anxiolytic, sympatholytic, and opioid-sparing properties. It reduces the need for anesthetics and opioids without causing respiratory depression but existing literature has reported conflicting results [17]. Many studies have already shown that OFA allows opioid sparing in the postoperative period. After bariatric [18] and spine surgery [19], OFA techniques led to lower morphine consumption and better postoperative analgesia. Liu et al. showed that dexmedetomidine may be a favorable anesthetic adjuvant in breast cancer surgery [20]. Dexmedetomidine has a range of perioperative applications, from reducing the hemodynamic response to tracheal intubation [21] to reducing the incidence of postoperative nausea and vomiting (PONV) [22]. In a meta-analysis, Grape et al. reported that dexmedetomidine was superior when compared to intraoperative remifentanil, with better pain outcomes postoperatively in the first $24 \mathrm{~h}$. In addition, dexmedetomidine has been linked to fewer episodes of 
hypotension, shivering, and PONV [17]. On the other hand, Beloeil $\mathrm{H}$ et al. reported higher rates of severe bradycardia with the use of dexmedetomidine-based, opioid-free anesthesia [23]. In addition, clinically significant hypotension, delay in discharge, and prolongation of hypoxia may be observed with dexmedetomidine infusion [9].

Ketamine, an N-methyl-D-aspartate (NMDA) receptor antagonist, is widely known as a dissociative anesthetic and phencyclidine derivative. It has complex hypnotic, analgesic, antidepressant and psychotomimetic effects that cannot be explained only by NMDA and receptor antagonism. Ketamine has also been shown to bind to all types of opioid receptors with the highest affinity for mu, kappa, and delta receptors [24]. Ketamine has a unique profile combining analgesia and sedation by dissociative effect. Its analgesic effect is dose dependent, and intravenous ketamine is an effective adjuvant for postoperative analgesia [25]. Ketamine leads to effective analgesia at subanesthetic doses ( $\leq 0.3 \mathrm{mg} / \mathrm{kg}$ intravenous) [26]. However, it should be cautiously used as only a single dose can lead to hallucinations and nightmares. Although the mechanism of opioid-induced hyperalgesia is not fully known, high activation and stimulation of NMDA receptors are among the leading hypotheses. Opioid-induced hyperalgesia is more common in patients using high-dose opioids for the treatment of cancer pain and ketamine is often used in the treatment of this condition given its effect on NMDA receptors [27]. Ketamine is in racemic form containing equal proportions of R-ketamine and S-ketamine. Sketamine has higher affinity for NMDA receptors than Rketamine, its anesthetic potency is 3-4 times higher and undesirable side effects are reduced [28]. There is evidence that ketamine infusion is useful for the management of chronic pain [29].. Because of these beneficial properties, the use of ketamine in cancer patients is increasing. Lidocaine is an amide group local anesthetic that is used clinically for analgesia. Infusion in the perioperative period is safe and has clear advantages, such as reduced postoperative pain, decreased length of hospital stay and PONV and perioperative opioid requirements as well as accelerated postoperative recovery of bowel function [25-32]. Perioperative intravenous lidocaine has been shown to have a positive effect on cancer outcomes in clinical studies. Additionally, the mechanism of this effect has been demonstrated in in vitro and animal studies [33]. In patients undergoing pancreatectomy, Zhang et al. found that those who received intravenous lidocaine preoperatively had a considerably improved overall survival [34]. Additional intravenous agents such as magnesium, steroids, $\beta$-blockers, and oral pregabalin have been shown to have beneficial effects in OFA, though more studies are needed for their use to become routinely part of OFA [9, 35-37].

\section{Regional anesthesia}

The use of regional anesthesia applications provides many essential benefits such as lower pain scores in the postoperative period, early hospital discharge, reduction in the incidence of PONV, and reduction in the use of additional analgesics. In addition, regional anesthesia is not only an important component of pain management: evidence suggests that it may also play a role in inhibiting cancer progression [38, 39].

The importance of regional anesthesia in accepting an opioid-free modality was demonstrated in a prospective study of 2382 upper and lower extremity peripheral nerve blocks, with $90 \%$ of patients not requiring opioids in the PACU postoperatively [40]. Therefore, regional anesthesia applications can be considered the cornerstone of OFA. Another entity is that inadequately treated acute postoperative pain may be associated with $10-50 \%$ of persistent postsurgical pain [41]. This is a significant contributor to long-term opioid overuse. A meta-analysis examined the effect of regional anesthetic techniques on the incidence of persistent postoperative pain. This meta-analysis found that regional anesthesia techniques significantly reduced the risk of persistent postoperative pain development compared to standard analgesia in breast surgery, thoracotomy, and cesarean section [42].

Epidural analgesia, thoracic paravertebral block, intercostal block, local infiltration analgesia, and transversus abdominis plane block are the most known and effective opioid-free regional anesthesia techniques [43]. Neuraxial analgesia minimizes perioperative opioid consumption in urological, thoracic, obstetric, orthopedic, and major abdominal surgeries. Epidural analgesia and continuous catheter techniques are used quite frequently, especially in open abdominal and thoracic surgeries [44]. Recently, a new horizon has been opened in OFA with the introduction of ultrasonography in regional anesthesia practice. It is claimed that not only neuraxial techniques but also interfacial plane blocks contribute positively to the opioid-free or opioid-sparing effect. Interfacial plane blocks may be a feasible option, especially in cases where neuraxial techniques cannot be applied or are contraindicated. Although there is not enough evidence yet, it has been shown in randomized controlled studies and case reports that interfacial plan blocks reduce opioid consumption or have an opioidfree anesthesia effect [45-47]. In a study comparing TAP block with liposomal bupivacaine and epidural analgesia, TAP block was shown to be an alternative to epidural analgesia for pain control in patients undergoing abdominal surgery [48]. TAP and quadratus lumborum blocks can be good alternatives in abdominal and obstetric surgeries, while pectoral and serratus plane blocks find use in breast and thoracic surgeries [49]. In 
thoracic and lumbar surgeries, erector spinae plane and thoracolumbar interfascial plane blocks are also potentially interesting techniques with opioid-sparing effects $[50,51]$. Another advantage of interfacial plane blocks in the opioid-free concept is the opportunity of inserting an indwelling catheter to maintain a continuous analgesic infusion.

\section{Non-pharmacological treatment}

In the setting of opioid-free analgesia, optimizing perioperative care with non-pharmacological strategies to mitigate nociception is a potentially understudied strategy, with literature currently dominated by studies on pharmacological interventions. Fiore et al., in a scoping review conducted in 2019, identified only 13 studies addressing specifically non-pharmacological interventions in opioid-free analgesia [52].

Transcutaneous electrical nerve stimulation (TENS) is one of the most studied non-pharmacologic strategies to improve analgesia in surgical patients and is used for pain management of both acute and chronic pain irrespective of cause. Though its role in postoperative analgesia may be yet controversial [53], TENS was found to substantially reduce postoperative analgesics consumption [54] and was beneficial on postoperative pain after thoracotomy, sternotomy, total knee arthroplasty, pulmonary surgery, and post-cesarean pain [55].

Acupuncture is another potential strategy to reduce pain in the postoperative period and was effective against controls in a randomized control trial on inguinal hernia repair [56]. Recent literature has been focused also on the use of electrical acupuncture, which was demonstrated to be more effective than traditional acupuncture in a randomized control trial on 121 patients requiring thyroid surgery [57].

Among other non-pharmacological interventions, sitz baths and moxibustion have been used after hemorrhoidectomy, [58] while aromatherapy was successfully used in pain relief after cesarean section and laparoscopic adjustable gastric banding, demonstrating that pain after surgery following inhalation of lavender essence was significantly decreased compared with the placebo groups [58, 59]. A 2016 systematic review and meta-analysis found that aromatherapy was effective in reducing pain scores in patients with acute and chronic pain, though the authors specify that the relatively few studies with substantially different protocols analyzing different types of pain may limit the strength of their conclusions [60].

Another potentially underestimated non-pharmacological strategy may involve the use of focussed preoperative patient education programs. A recent systematic review in orthopedic surgery concludes that multimodal preoperative education programs hold promise as an effective strategy to limit opioid consumption in the postoperative period [61].
In gynecological and abdominal surgery patients, preoperative counseling on postoperative pain management and on opioid medication adverse effects has been shown to reduce the consumption of opioids, with equivalent pain scores and medication refill requests [62].

Currently, a growing body of scientific evidence suggests that non-pharmacological strategies may have substantial effects in the treatment of both acute and chronic pain, though more large and well-designed studies are needed to reach a consensus regarding opioidsparing analgesia in cancer surgery. Furthermore, among non-pharmacological strategies, other potential treatment modalities, such as relaxation, imagery/hypnosis, cognitive behavioral therapy/coping skills training, and meditation have not been studied extensively in the post-surgical setting and may also warrant future investigation [63].

\section{"Opioid-free anesthesia" and unintended consequences}

As a reflexive response to the opioid epidemic, there have been a number of "opioid-free anesthesia" protocols shared within the anesthesia community [64]. In general, these approaches specifically target the avoidance of one class of medications and focus only on the time that patients spend within the operating room walls [65].

As anesthesiologists and acute pain medicine specialists, it is critical to acknowledge the important role of opioids in perioperative pain management, especially in the context of treating visceral pain [66]. While avoiding the potentially harmful effect of opioids is important, opioids may be prescribed safely by anesthesiologists and surgeons in the perioperative period when following appropriate guidelines [67]. Seven principles of acute perioperative pain management have been endorsed by 14 medical organizations in the USA and were recently published [68]. These principles emphasize the routine use of multimodal analgesia with the primary goal of improving the quality of pain management. Multimodal analgesic regimens frequently include non-pharmacologic interventions, non-opioid systemic analgesics, and local anesthesia and regional block techniques [68]. Patients' requirement for opioids reliably decreases with the effective use of multimodal analgesia, but this is a side benefit while the goal is better perioperative pain management.

The deliberate restriction of opioids when they may be indicated, limiting them to the time when patients are in the operating room, may have unintended consequences. In a study of patients who underwent major non-cardiac surgery, patients assigned to an intraoperative opioidfree anesthesia protocol featuring dexmedetomidine experienced more postoperative side effects such as bradycardia, hypoxemia, and prolonged recovery than the opioid-exposed group [23]. Numerous experts, including 
the authors of the Centers for Disease Control and Prevention Chronic Opioid Prescribing Guideline [69], have expressed concern about the inappropriate restriction of opioids for acute pain [70-72]. There is no evidence that opioid-free anesthesia protocols decrease long-term postoperative opioid use.

An appropriate opioid stewardship plan must extend beyond the immediate intraoperative period $[65,67,72]$. It does not make sense to avoid opioids when patients are under anesthesia, only to then expose them to opioids as soon as they arrive in the postanesthesia care unit and during the rest of their hospital stay, and finally discharging them home with an arbitrary number of opioid tablets. Opioid-sparing multimodal analgesia must be continued after surgery for all patients on an inpatient and outpatient basis [73]. To date, only programs that have incorporated postdischarge opioid stewardship with individualized prescribing and tapering have demonstrated decreases in outpatient opioid use [74, 75].

\section{Future insights}

Over the past two decades, opioids have increasingly been prescribed for the treatment of various chronic pain conditions and during the perioperative period. Opioids have multiple side effects, especially in elderly patients. Recent studies have also shown that the use of opioids in patients undergoing surgery is responsible for worse outcomes, an increase in the length of hospital stay, and an increase in healthcare costs [76].

OFA has gained in popularity as a way to enhance early recovery and to spare opioids for the postoperative period. While opioid-sparing strategies are recommended, little data exists on the feasibility of OFA in routine practice. However, promising results were obtained with OFA strategies, as described above. In the era of ERAS protocols, the use of multimodal analgesia with combinations of analgesic drugs and local regional anesthesia techniques is imperative $[77,78]$. All this is in the effort to minimize the consumption of opioids and their side effects, moving from a present of opioid sparing to a future of opioid-free anesthesia [79, 80].

\section{Conclusions}

Choosing the best anesthesia protocol for a patient undergoing surgery for cancer is not an easy task and the literature provides no definitive answers. However, in cancer patients, a pragmatic approach can be suggested considering the available options and the feasibility in the different settings. When possible, OFA strategies should be considered while ensuring that optimal pain management is achieved. Opioid administration may be needed but should be used in the lowest effective doses as part of multimodal analgesia.
Considering the benefits and low risks, comprehensive patient education programs should be considered, as well as other non-pharmacological interventions when applicable. More well-designed studies are needed to reach a definitive conclusion on OFA in cancer surgery.

\section{Abbreviations \\ ERAS: Enhanced Recovery After Surgery; NMDA: N-methyl-D-aspartate; OFA: Opioid-free anesthesia; PONV: Postoperative nausea and vomiting; TENS: Transcutaneous electrical nerve stimulation}

\section{Acknowledgements \\ None}

\section{Authors' contributions}

Study conception: ADC; Study design: ADC; Research proposal: By invitation; Data collection: All the authors; Writing of paper: All the authors; Editing of paper: All the authors. The authors read and approved the final manuscript.

Funding

None

Availability of data and materials

Data sharing is not applicable to this article as no datasets were generated or analyzed during the current study.

\section{Declarations}

Ethics approval and consent to participate

Not applicable

Consent for publication

Not applicable

\section{Competing interests}

The authors declare that they have no competing interests.

\section{Author details}

${ }^{1}$ UOC Anaesthesia and Intensive Care Unit, University Hospital of Padua, Via Giustiniani 1, 35127 Padua, Italy. ${ }^{2}$ Samsun University Faculty of Medicine, Training and Research Hospital, Samsun, Samsun, Turkey. ${ }^{3}$ Department of Anesthesiology and Reanimation, Ataturk University Faculty of Medicine, Erzurum, Turkey. ${ }^{4}$ Clinical Research, Development and Design Application and Research Center, Ataturk University School of Medicine, Erzurum, Turkey. ${ }^{5}$ Anesthesiology and Perioperative Care Service, Veterans Affairs Palo Alto Health Care System, Palo Alto, CA, USA. ${ }^{6}$ Department of Anesthesiology, Perioperative and Pain Medicine, Stanford University School of Medicine, Stanford, CA, USA. ${ }^{7}$ Department of Anesthesiology and Reanimation, Ondokuz Mayis University Faculty of Medicine, Samsun, Turkey. ${ }^{8}$ Department of Anesthesia and Intensive Care Unit, San Salvatore Academic Hospital of L'Aquila, L'Aquila, Italy. ${ }^{9}$ Department of Life, Health and Environmental Sciences, University of L'Aquila, L'Aquila, Italy. ${ }^{10}$ Unit of Anaesthesia, Intensive Care and Pain Management, Department of Medicine, Università Campus Bio-Medico di Roma, Rome, Italy. ${ }^{11}$ University of Padova, Department of Medicine, Padua, Italy.

Received: 30 November 2021 Accepted: 20 January 2022

Published online: 05 February 2022

\section{References}

1. Meissner W, Zaslansky R (2019) A survey of postoperative pain treatments and unmet needs. Best Pract Res Clin Anaesthesiol 33(3):269-286. https:// doi.org/10.1016/j.bpa.2019.10.003

2. Roth RS, Qi J, Hamill JB, Kim HM, Ballard T, Pusic AL, Wilkins EG (2018) Is chronic postsurgical pain surgery-induced? A study of persistent postoperative pain following breast reconstruction. Breast (Edinburgh, Scotland) 37:119-125

3. Colvin LA, Bull F, Hales TG (2019) Perioperative opioid analgesia-when is enough too much? A review of opioid-induced tolerance and hyperalgesia. 
Lancet (London, England) 393(10180):1558-1568. https://doi.org/10.1016/ S0140-6736(19)30430-1

4. Nelson LS, Juurlink DN, Perrone J (2015) Addressing the Opioid Epidemic. JAMA 314(14):1453-1454. https://doi.org/10.1001/jama.2015.12397

5. Vadivelu N, Kai AM, Kodumudi V, Sramcik J, Kaye AD (2018) The opioid crisis: a comprehensive overview. Curr Pain Headache Rep 22(3):16. https:// doi.org/10.1007/s1 1916-018-0670-z

6. Nelson G, Bakkum-Gamez J, Kalogera E, Glaser G, Altman A, Meyer LA, Taylor JS, Iniesta M, Lasala J, Mena G, Scott M, Gillis C, Elias K, Wijk L, Huang J, Nygren J, Ljungqvist O, Ramirez PT, Dowdy SC (2019) Guidelines for perioperative care in gynecologic/oncology: Enhanced Recovery After Surgery (ERAS) Society recommendations-2019 update. Int J Gynecol Cancer 29(4):651-668. https://doi.org/10.1136/ijgc-2019-000356

7. Beloeil H (2019) Opioid-free anesthesia. Best practice \& research. Clin Anaesthesiol 33(3):353-360. https://doi.org/10.1016/j.bpa.2019.09.002

8. Soffin EM, Lee BH, Kumar KK, Wu CL (2019) The prescription opioid crisis: role of the anaesthesiologist in reducing opioid use and misuse. Brit J Anaesthesia 122(6):e198-e208. https://doi.org/10.1016/j.bja.2018.11.019

9. Shanthanna H, Ladha KS, Kehlet H, Joshi GP (2021) Perioperative Opioid Administration. Anesthesiology 134(4):645-659. https://doi.org/10.1097/ALN. 0000000000003572

10. Ferlay J, Colombet M, Soerjomataram I, Parkin DM, Piñeros M, Znaor A, Bray F (2021) Cancer statistics for the year 2020: an overview. Int J Cancer. https://doi. org/10.1002/ijc.33588. Advance online publication. 149, 4, 778, 789

11. Sultana A, Torres D, Schumann R (2017) Special indications for opioid free anaesthesia and analgesia, patient and procedure related: including obesity, sleep apnoea, chronic obstructive pulmonary disease, complex regional pain syndromes, opioid addiction and cancer surgery. Best practice \& research. Clin Anaesthesiol 31(4):547-560. https://doi.org/10.1016/j.bpa.201 7.11 .002

12. Afsharimani B, Cabot P, Parat MO (2011) Morphine and tumor growth and metastasis. Cancer metastasis reviews 30(2):225-238. https://doi.org/10.1007/ s10555-011-9285-0

13. Bugada D, Lorini LF, Lavand'homme P (2021) Opioid free anesthesia: evidence for short and long-term outcome. Minerva Anestesiologica 87(2): 230-237. https://doi.org/10.23736/S0375-9393.20.14515-2

14. Wall T, Sherwin A, Ma D, Buggy DJ (2019) Influence of perioperative anaesthetic and analgesic interventions on oncological outcomes: a narrative review. British journal of anaesthesia 123(2):135-150. https://doi. org/10.1016/j.bja.2019.04.062

15. Sessler DI, Pei L, Huang Y, Fleischmann E, Marhofer P, Kurz A, Mayers DB, Meyer-Treschan TA, Grady M, Tan EY, Ayad S, Mascha EJ, Buggy DJ, Breast Cancer Recurrence Collaboration (2019) Recurrence of breast cancer after regional or general anaesthesia: a randomised controlled trial. Lancet (London, England) 394(10211):1807-1815. https://doi.org/10.1016/S0140-673 6(19)32313-X

16. Olausson A, Svensson CJ, Andréll P, Jildenstål P, Thörn SE, Wolf A (2021) Total opioid-free general anaesthesia can improve postoperative outcomes after surgery, without evidence of adverse effects on patient safety and pain management: a systematic review and meta-analysis. Acta Anaesthesiol Scand. https://doi.org/10.1111/aas.13994. Advance online publication. , 66, 2, 170, 185

17. Grape S, Kirkham KR, Frauenknecht J, Albrecht E (2019) Intra-operative analgesia with remifentanil vs. dexmedetomidine: a systematic review and meta-analysis with trial sequential analysis. Anaesthesia 74(6):793-800. https://doi.org/10.1111/anae.14657

18. Feld JM, Hoffman WE, Stechert MM, Hoffman IW, Ananda RC (2006) Fentanyl or dexmedetomidine combined with desflurane for bariatric surgery. J Clin Anesthesia 18(1):24-28. https://doi.org/10.1016/j.jclinane.2005. 05.009

19. Hwang W, Lee J, Park J, Joo J (2015) Dexmedetomidine versus remifentani in postoperative pain control after spinal surgery: a randomized controlled study. BMC Anesthesiol 15(1):21. https://doi.org/10.1186/s12871-015-0004-1

20. Liu C, Wang W, Shan Z, Zhang H, Yan Q (2020) Dexmedetomidine as an adjuvant for patients undergoing breast cancer surgery: a meta-analysis. Medicine 99(50):e23667. https://doi.org/10.1097/MD.0000000000023667

21. De Cassai A, Boscolo A, Geraldini F, Zarantonello F, Pettenuzzo T, Pasin L, luzzolino M, Rossini N, Pesenti E, Zecchino G, Sella N, Munari M, Navalesi P (2021) Effect of dexmedetomidine on hemodynamic responses to tracheal intubation: a meta-analysis with meta-regression and trial sequential analysis. Journal of clinical anesthesia 72:110287. https://doi.org/10.1016/j. jclinane.2021.110287

22. Ziemann-Gimmel P, Goldfarb AA, Koppman J, Marema RT (2014) Opioid-free total intravenous anaesthesia reduces postoperative nausea and vomiting in bariatric surgery beyond triple prophylaxis. Brit J Anaesthesia 112(5):906911. https://doi.org/10.1093/bja/aet551

23. Beloeil H, Garot M, Lebuffe G, Gerbaud A, Bila J, Cuvillon P, Dubout E, Oger S, Nadaud J, Becret A, Coullier N, Lecoeur S, Fayon J, Godet T, Mazerolles M, Atallah F, Sigaut S, Choinier PM, Asehnoune K, Roquilly A et al (2021) Balanced Opioid-free Anesthesia with Dexmedetomidine versus Balanced Anesthesia with Remifentanil for Major or Intermediate Noncardiac Surgery. Anesthesiology 134(4):541-551. https://doi.org/10.1 097/ALN.0000000000003725

24. Sleigh J, Harvey M, Voss L, Denny B (2014) Ketamine - More mechanisms of action than just NMDA blockade. Trends Anaesth Crit Care 4(2-3):76-81. https://doi.org/10.1016/j.tacc.2014.03.002

25. Laskowski K, Stirling A, McKay WP, Lim HJ (2011) A systematic review of intravenous ketamine for postoperative analgesia. Can J Anesth Can d'anesthésie:58. https://doi.org/10.1007/s12630-011-9560-0

26. Gorlin A, Rosenfeld D, Ramakrishna H (2016) Intravenous sub-anesthetic ketamine for perioperative analgesia. J Anaesthesiol Clin Pharmacol 32(2): 160-167. https://doi.org/10.4103/0970-9185.182085

27. Lee M, Silverman SM, Hansen H, Patel VB, Manchikanti L (2011) A comprehensive review of opioid-induced hyperalgesia. Pain physician 14(2): 145-161. https://doi.org/10.36076/ppj.2011/14/145

28. Domino EF (2010) Taming the ketamine tiger 1965. Anesthesiology 113(3): 678-684. https://doi.org/10.1097/ALN.0b013e3181ed09a2

29. Cohen SP, Bhatia A, Buvanendran A, Schwenk ES, Wasan AD, Hurley RW, Viscusi ER, Narouze S, Davis FN, Ritchie EC, Lubenow TR, Hooten WM (2018) Consensus guidelines on the use of intravenous ketamine infusions for chronic pain from the American Society of Regional Anesthesia and Pain Medicine, the American Academy of Pain Medicine, and the American Society of Anesthesiologists. Reg Anesth Pain Med 43(5):521-546. https:// doi.org/10.1097/AAP.0000000000000808

30. Kranke P, Jokinen J, Pace NL, Schnabel A, Hollmann MW, Hahnenkamp K, Eberhart LH, Poepping DM, Weibel S (2015) Continuous intravenous perioperative lidocaine infusion for postoperative pain and recovery. Cochrane Database Syst Rev 7(7):CD009642. https://doi.org/10.1002/14651 858.CD009642.pub2

31. Bakan M, Umutoglu T, Topuz U, Uysal H, Bayram M, Kadioglu H, Salihoglu Z (2015) Opioid-free total intravenous anesthesia with propofol, dexmedetomidine and lidocaine infusions for laparoscopic cholecystectomy: a prospective, randomized, double-blinded study. Braz J Anesthesiol (Elsevier) 65(3):191-199. https://doi.org/10.1016/j.bjane.2014.05.001

32. Song $X$, Sun $Y$, Zhang $X, L i T$, Yang B (2017) Effect of perioperative intravenous lidocaine infusion on postoperative recovery following laparoscopic cholecystectomy-a randomized controlled trial. International journal of surgery (London, England), 45, 8-13. https://doi.org/10.1016/j. ijsu.2017.07.042

33. Wall TP, Buggy DJ (2021) Perioperative intravenous lidocaine and metastatic cancer recurrence - a narrative review. Front Oncol 11:688896. https://doi. org/10.3389/fonc.2021.688896

34. Zhang H, Yang L, Zhu X, Zhu M, Sun Z, Cata JP, Chen W, Miao C (2020) Association between intraoperative intravenous lidocaine infusion and survival in patients undergoing pancreatectomy for pancreatic cancer: a retrospective study. Brit J Anaesthesia 125(2):141-148. https://doi.org/10.101 6/j.bja.2020.03.034

35. Ladha KS, Patorno E, Huybrechts KF, Liu J, Rathmell JP, Bateman BT (2016) Variations in the Use of Perioperative Multimodal Analgesic Therapy. Anesthesiology 124(4):837-845. https://doi.org/10.1097/ALN. 0000000000001034

36. Gelineau AM, King MR, Ladha KS, Burns SM, Houle T, Anderson TA (2018) Intraoperative esmolol as an adjunct for perioperative opioid and postoperative pain reduction: a systematic review, meta-analysis, and metaregression. Anesthesia Analgesia 126(3):1035-1049. https://doi.org/10.1213/A NE.0000000000002469

37. Mishriky BM, Waldron NH, Habib AS (2015) Impact of pregabalin on acute and persistent postoperative pain: a systematic review and meta-analysis. Brit J Anaesthesia 114(1):10-31. https://doi.org/10.1093/bja/aeu293

38. Grandhi RK, Lee S, Abd-Elsayed A (2017) The relationship between regional anesthesia and cancer: a metaanalysis. Ochsner J 17(4):345-361 
39. Garg R (2017) Regional anaesthesia in breast cancer: benefits beyond pain. Indian J Anaesth 61(5):369-372. https://doi.org/10.4103/ija.IJA_292_17

40. Klein SM, Nielsen KC, Greengrass RA, Warner DS, Martin A, Steele SM (2002) Ambulatory discharge after long-acting peripheral nerve blockade: 2382 blocks with ropivacaine. Anesthesia Analgesia 94(1). https://doi.org/10.1097/ 00000539-200201000-00012

41. Chapman CR, Vierck CJ (2017) The transition of acute postoperative pain to chronic pain: an integrative overview of research on mechanisms. J Pain 18(4):359.e1-359.e38. https://doi.org/10.1016/j.jpain.2016.11.004

42. Weinstein EJ, Levene $J$, Cohen MS, Andreae DA, Chao JY, Johnson M, Hall CB, Andreae MH (2018) Local anaesthetics and regional anaesthesia versus conventional analgesia for preventing persistent postoperative pain in adults and children. Cochrane Database Syst Rev 6(6):CD007105. https://doi. org/10.1002/14651858.CD007105.pub4

43. Baboli KM, Liu H, Poggio JL (2020) Opioid-free postoperative analgesia: is it feasible? Current problems in surgery 57(7):100794. https://doi.org/10.1016/j. cpsurg.2020.100794

44. Kumar K, Kirksey MA, Duong S, Wu CL (2017) A review of opioid-sparing modalities in perioperative pain management: methods to decrease opioid use postoperatively. Anesthesia and analgesia 125(5):1749-1760. https://doi. org/10.1213/ANE.0000000000002497

45. Morgenstern C, Ramírez-Paesano C, Juanola Galcerán A, Morgenstern R (2021) Thoracolumbar interfascial plane block results in opioid-free postoperative recovery after percutaneous/endoscopic transforaminal lumbar interbody fusion surgery. World neurosurgery 153:e473-e480. https://doi.org/10.1016/j.wneu.2021.06.152

46. Luis-Navarro JC, Fornés-Rumbao C, DeLaCalle-Gil AB, Forero M (2020) Multimodal anesthesia via opioid-free analgesia and erector spinae plane block. Case reports in anesthesiology 2020:6062935. https://doi.org/10.1155/2020/6062935

47. Chin KJ, Lewis S (2019) Opioid-free analgesia for posterior spinal fusion surgery using erector spinae plane (ESP) blocks in a multimodal anesthetic regimen. Spine 44(6):E379-E383. https://doi.org/10.1097/BRS.0000000000002855

48. Ayad S, Babazade R, Elsharkawy H, Nadar V, Lokhande C, Makarova N, Khanna R, Sessler DI, Turan A (2016) Comparison of transversus abdominis plane infiltration with liposomal bupivacaine versus continuous epidural analgesia versus intravenous opioid analgesia. Plos one 11(4):e0153675. https://doi.org/10.1371/journal.pone.0153675

49. De Cassai A, Bonanno C, Sandei L, Finozzi F, Carron M, Marchet A (2019) PECS $\|$ block is associated with lower incidence of chronic pain after breast surgery. Korean J Pain 32(4):286-291. https://doi.org/10.3344/kjp.2019.32.4.286

50. Yayik AM, Cesur S, Ozturk F, Ahiskalioglu A, Ay AN, Celik EC, Karaavci NC (2019) Postoperative analgesic efficacy of the ultrasound-guided erector spinae plane block in patients undergoing lumbar spinal decompression surgery: a randomized controlled study. World neurosurgery 126:e779-e785. https://doi.org/10.1016/j.wneu.2019.02.149

51. Ahiskalioglu A, Yayik AM, Doymus O, Selvitopi K, Ahiskalioglu EO, Calikoglu C, Alici HA, Karaca O (2018) Efficacy of ultrasound-guided modified thoracolumbar interfascial plane block for postoperative analgesia after spinal surgery: a randomized-controlled trial. Can J Anaesth 65(5):603-604. https://doi.org/10.1007/s12630-018-1051-0

52. Fiore JF Jr, Olleik G, El-Kefraoui C, Verdolin B, Kouyoumdjian A, Alldrit A, Figueiredo AG, Valanci S, Marquez-GdeV JA, Schulz M, Moldoveanu D, Nguyen-Powanda P, Best G, Banks A, Landry T, Pecorelli N, Baldini G, Feldman LS (2019) Preventing opioid prescription after major surgery: a scoping review of opioid-free analgesia. Brit J Anaesthesia 123(5):627-636. https://doi.org/10.1016/j.bja.2019.08.014

53. Kerai S, Saxena KN, Taneja B, Sehrawat L (2014) Role of transcutaneous electrical nerve stimulation in post-operative analgesia. Indian journal of anaesthesia 58(4):388-393. https://doi.org/10.4103/0019-5049.138966

54. Bjordal JM, Johnson MI, Ljunggreen AE (2003) Transcutaneous electrical nerve stimulation (TENS) can reduce postoperative analgesic consumption. A meta-analysis with assessment of optimal treatment parameters for postoperative pain. Eur J Pain (London, England) 7(2):181-188. https://doi. org/10.1016/S1090-3801(02)00098-8

55. Paley CA, Wittkopf PG, Jones G, Johnson MI (2021) Does TENS reduce the intensity of acute and chronic pain? A comprehensive appraisal of the characteristics and outcomes of 169 reviews and 49 meta-analyses. Medicina (Kaunas, Lithuania) 57(10):1060. https://doi.org/10.3390/medicina57101060

56. Taghavi R, Tabasi KT, Mogharabian N, Asadpour A, Golchian A, Mohamadi S, Kabiri AA (2013) The effect of acupuncture on relieving pain after inguinal surgeries. Korean J Pain 26(1):46-50. https://doi.org/10.3344/kjp.2013.26.1.46
57. lacobone M, Citton M, Zanella S, Scarpa M, Pagura G, Tropea S, Galligioni H, Ceccherelli F, Feltracco P, Viel G, Nitti D (2014) The effects of acupuncture after thyroid surgery: A randomized, controlled trial. Surgery 156(6):16051613. https://doi.org/10.1016/j.surg.2014.08.062

58. Olapour A, Behaeen K, Akhondzadeh R, Soltani F, Al Sadat Razavi F, Bekhradi $R$ (2013) The effect of inhalation of aromatherapy blend containing lavender essential oil on cesarean postoperative pain. Anesth Pain Med 3(1):203-207. https://doi.org/10.5812/aapm.9570

59. Kim JT, Ren CJ, Fielding GA, Pitti A, Kasumi T, Wajda M, Lebovits A, Bekker A (2007) Treatment with lavender aromatherapy in the post-anesthesia care unit reduces opioid requirements of morbidly obese patients undergoing laparoscopic adjustable gastric banding. Obesity surgery 17(7):920-925. https://doi.org/10.1007/s11695-007-9170-7

60. Lakhan SE, Sheafer H, Tepper D (2016) The effectiveness of aromatherapy in reducing pain: a systematic review and meta-analysis. Pain research and treatment 2016:8158693. https://doi.org/10.1155/2016/8158693

61. Rucinski K, Cook JL (2020) Effects of preoperative opioid education on postoperative opioid use and pain management in orthopaedics: a systematic review. J Orthopaedics 20:154-159. https://doi.org/10.1016/j.jor.2 020.01.020

62. Mark J, Argentieri DM, Gutierrez CA, Morrell K, Eng K, Hutson AD, Mayor P, Szender JB, Starbuck K, Lynam S, Blum B, Akers S, Lele S, Paragh G, Odunsi K, de Leon-Casasola O, Frederick PJ, Zsiros E (2018) Ultrarestrictive opioid prescription protocol for pain management after gynecologic and abdominal surgery. JAMA network open 1(8):e185452. https://doi.org/10.1 001/jamanetworkopen.2018.5452

63. Tick H, Nielsen A, Pelletier KR, Bonakdar R, Simmons S, Glick R, Ratner E, Lemmon RL, Wayne P, Zador V, Pain Task Force of the Academic Consortium for Integrative Medicine and Health (2018) Evidence-based nonpharmacologic strategies for comprehensive pain care: the Consortium Pain Task Force White Paper. Explore (New York, N.Y.). 14(3), 177-211. https://doi.org/10.1016/j.explore.2018.02.001

64. Boysen PG 2nd, Pappas MM, Evans B (2018) An evidence-based opioid-free anesthetic technique to manage perioperative and periprocedural pain. Ochsner J 18(2):121-125. https://doi.org/10.31486/toj.17.0072

65. Elkassabany NM, Mariano ER (2019) Opioid-free anaesthesia - what would Inigo Montoya say? Anaesthesia 74(5):560-563. https://doi.org/10.1111/ana e.14611

66. Boezaart AP, Smith CR, Chembrovich S, Zasimovich Y, Server A, Morgan G, Theron A, Booysen K, Reina MA (2021) Visceral versus somatic pain: an educational review of anatomy and clinical implications. Reg Anesthesia Pain Med 46(7):629-636. https://doi.org/10.1136/rapm-2020-102084

67. Levy N, Quinlan J, El-Boghdadly K, Fawcett WJ, Agarwal V, Bastable RB, Cox FJ, de Boer HD, Dowdy SC, Hattingh K, Knaggs RD, Mariano ER, Pelosi P, Scott MJ, Lobo DN, Macintyre PE (2021) An international multidisciplinary consensus statement on the prevention of opioid-related harm in adult surgical patients. Anaesthesia 76(4):520-536. https://doi.org/10.1111/anae.1 5262

68. Mariano ER, Dickerson DM, Szokol JW, Harned M, Mueller JT, Philip BK, Baratta JL, Gulur P, Robles J, Schroeder KM, Wyatt K, Schwalb JM, Schwenk ES, Wardhan R, Kim TS, Higdon KK, Krishnan DG, Shilling AM, Schwartz G, Wiechmann L, Buvanendran A (2021) A multisociety organizational consensus process to define guiding principles for acute perioperative pain management. Regional anesthesia and pain medicine, rapm-2021-103083. Advance online publication. https://doi. org/10.1136/rapm-2021-103083

69. Dowell D, Haegerich TM, Chou R (2016) CDC guideline for prescribing opioids for chronic pain--United States, 2016. JAMA 315(15):1624-1645. https://doi.org/10.1001/jama.2016.1464

70. Dowell D, Haegerich T, Chou R (2019) No shortcuts to safer opioid prescribing. The New England journal of medicine 380(24):2285-2287. https://doi.org/10.1056/NEJMp1904190

71. Kharasch ED, Avram MJ, Clark JD (2020) Rational perioperative opioid management in the era of the opioid crisis. Anesthesiology 132(4):603-605. https://doi.org/10.1097/ALN.0000000000003166

72. Lirk P, Rathmell JP (2019) Opioid-free anaesthesia: con: it is too early to adopt opioid-free anaesthesia today. Euro J Anaesthesiol 36(4):250-254. https://doi.org/10.1097/EJA.0000000000000965

73. Mariano ER, Schatman ME (2019) A commonsense patient-centered approach to multimodal analgesia within surgical enhanced recovery protocols. J Pain Res 12:3461-3466. https://doi.org/10.2147/JPR.S238772 
74. Joo SS, Hunter OO, Tamboli M, Leng JC, Harrison TK, Kassab K, Keeton JD, Skirboll S, Tharin S, Saleh E, Mudumbai SC, Wang RR, Kou A, Mariano ER (2020) Implementation of a patient-specific tapering protocol at discharge decreases total opioid dose prescribed for 6 weeks after elective primary spine surgery. Reg Anesthesia Pain Med 45(6):474-478. https://doi.org/1 0.1136/rapm-2020-101324

75. Tamboli M, Mariano ER, Gustafson KE, Briones BL, Hunter OO, Wang RR, Harrison TK, Kou A, Mudumbai SC, Kim TE, Indelli PF, Giori NJ (2020) A multidisciplinary patient-specific opioid prescribing and tapering protocol is associated with a decrease in total opioid dose prescribed for six weeks after total hip arthroplasty. Pain medicine (Malden, Mass.) 21(7):1474-1481. https://doi.org/10.1093/pm/pnz260

76. Lavand'homme P, Estebe JP (2018) Opioid-free anesthesia: a different regard to anesthesia practice. Current opinion in anaesthesiology 31(5):556-561. https://doi.org/10.1097/ACO.0000000000000632

77. Bonvicini D, De Cassai A, Andreatta G, Salvagno M, Carbonari I, Carere A, Fornasier M, lori D, Negrello M, Grutta G, Navalesi P (2021) Breast Regional Anesthesia Practice in the Italian Public Health System (BRA-SURVEY): a survey-based national study. Anesthesia Analgesia 133(3):772-780. https:// doi.org/10.1213/ANE.0000000000005649

78. De Cassai A, Boscolo A, Zarantonello F, Piasentini E, Di Gregorio G, Munari M, Persona P, Zampirollo S, Zatta M, Navalesi P (2021) Serratus anterior plane block for video-assisted thoracoscopic surgery: a meta-analysis of randomised controlled trials. European journal of anaesthesiology 38(2):106114. https://doi.org/10.1097/EJA.0000000000001290

79. Beverly A, Kaye AD, Ljungqvist O, Urman RD (2017) Essential elements of multimodal analgesia in Enhanced Recovery After Surgery (ERAS) Guidelines. Anesthesiology clinics 35(2):e115-e143. https://doi.org/10.1016/ j.anclin.2017.01.018

80. Fanelli A, Torrano V, Cozowicz C, Mariano ER, Balzani E (2021) The opioid sparing effect of erector spinae plane block for various surgeries: a metaanalysis of randomized-controlled trials. Minerva anestesiologica 87(8):903914. https://doi.org/10.23736/S0375-9393.21.15356-8

\section{Publisher's Note}

Springer Nature remains neutral with regard to jurisdictional claims in published maps and institutional affiliations.

Ready to submit your research? Choose BMC and benefit from:

- fast, convenient online submission

- thorough peer review by experienced researchers in your field

- rapid publication on acceptance

- support for research data, including large and complex data types

- gold Open Access which fosters wider collaboration and increased citations

- maximum visibility for your research: over $100 \mathrm{M}$ website views per year

At $\mathrm{BMC}$, research is always in progress.

Learn more biomedcentral.com/submissions 